\title{
Axon growth and guidance genes identify T-dependent germinal centre B cells
}

\author{
Di Yu ${ }^{1}$, Matthew C Cook ${ }^{2}$, Dong-Mi Shin ${ }^{3}$, Diego G Silva ${ }^{1}$, Jennifer Marshall ${ }^{4}$, Kai-Michael Toellner ${ }^{4}$, \\ Wendy L Havran ${ }^{5}$, Pico Caroni ${ }^{6}$, Michael P Cooke ${ }^{7}$, Herbert C Morse ${ }^{3}$, Ian CM MacLennan ${ }^{4}$, \\ Christopher C Goodnow ${ }^{1,8}$ and Carola G Vinuesa ${ }^{1}$
}

Selection of B cells subjected to hypermutation in germinal centres (GC) during T cell-dependent (TD) antibody responses yields memory cells and long-lived plasma cells that produce high affinity antibodies biased to foreign antigens rather than self-antigens. GC also form in T-independent (TI) responses to polysaccharide antigens but failed selection results in GC involution and memory cells are not generated. To date there are no markers that allow phenotypic distinction of T-dependent and TI germinal centre B cells. We compared the global gene expression of GC B cells purified from mice immunized with either TD or TI antigens and identified eighty genes that are differentially expressed in TD GC. Significantly, the largest cluster comprises genes involved in growth and guidance of neuron axons such as Plexin B2, Basp1, Nelf, Shh, Sc4mol and Sult4a. This is consistent with formation of long neurite (axon and dendrite)-like structures by mouse and human GC B cells, which may facilitate T:B cell interactions within GC, affinity maturation and B cell memory formation. Expression of BASP1 and PLEXIN B2 protein is very low or undetectable in resting and TI GC B cells, but markedly upregulated in GC B cells induced in the presence of $T$ cell help. Finally we show some of the axon growth genes upregulated in TD-GC B cells including Basp1, Shh, Sult4a, Sc4mol are also preferentially expressed in post-GC B cell neoplasms.

Immunology and Cell Biology (2008) 86, 3-14; doi:10.1038/sj.icb.7100123; published online 16 October 2007

Keywords: axon; B cell memory; germinal centre; T-dependent

During T cell-dependent (TD) immune responses, recently stimulated $B$ cells receive help from primed $T$ cells in the outer $T$ zones of secondary lymphoid tissues. B cells either differentiate extrafollicularly into mostly short-lived unmutated plasma cells or seed follicles and initiate germinal centre (GC) reactions. ${ }^{1}$ GC are a hallmark of antibody-mediated immune responses to $\mathrm{TD}$ antigens, giving rise to memory B cells and long-lived plasma cells that express modified immunoglobulin (Ig) genes that encode antibody with high affinity for antigen (affinity maturation).

Mature GC segregate into dark and light zones. The prevailing model of GC function describes centroblast (CB) proliferation in the dark zone where somatic hypermutation takes place. ${ }^{1}$ This represents the first step in affinity maturation, and since base changes are introduced stochastically, it results in Ig with a wide range of affinities for the immunizing antigen. $\mathrm{CB}$ differentiate into centrocytes (CC) that occupy the light zone. Recent evidence from live-imaging of GC dynamics confirms that there is constant B cell traffic between dark and light zones, and cell division occurs in both zones. ${ }^{2-4}$ Affinity maturation depends on CC selection based on their ability to interact with follicular dendritic cells, take up antigen held in the form of immune complexes, present it to antigen-specific follicular helper $\mathrm{T}$ cells $\left(\mathrm{T}_{\mathrm{FH}}\right)$ and elicit selection signals. ${ }^{5} \mathrm{~T}-\mathrm{B}$ interactions are remarkably transient, unstable and promiscuous, and B cell competition for $\mathrm{T}$ cell help is likely to be crucial for affinity maturation. ${ }^{6}$ CC expressing high-affinity and non-self-reactive antibody are positively selected to differentiate into long-lived plasma cells or memory B cells. By contrast, low affinity ${ }^{7-9}$ or self-reactive CC that fail selection undergo apoptosis. ${ }^{10-12}$ Thus T cell-mediated CC selection within GC provides the basis for affinity maturation of the antibody response and $\mathrm{B}$ cell memory formation. The signals that initiate CC differentiation into either memory cells or plasma cells are only partially understood.

Together with others, we have previously observed that under exceptional circumstances, GC can also be induced by T-independent type 2 (TI-2) antigens, ${ }^{13-15}$ but unlike GC induced by TD antigens, T-independent (TI) GC abort at the time CC would normally undergo $\mathrm{T}_{\mathrm{FH}}$-driven selection. This happens after minimal hypermutation, ${ }^{16}$

\footnotetext{
${ }^{1}$ Division of Immunology and Genetics, John Curtin School of Medical Research, The Australian National University, Canberra, Australia; ${ }^{2}$ Australian National University Medical School, Canberra, Australia; ${ }^{3}$ Laboratory of Immunopathology, National Institute of Allergy and Infectious Diseases, National Institute of Health, Rockville, MD, USA; ${ }^{4}$ MRC Centre for Immune Regulation, University of Birmingham, Birmingham, UK; ${ }^{5}$ Department of Immunology, The Scripps Research Institute, La Jolla, CA, USA; ${ }^{6}$ riedrich Miescher Institute, Basel, Switzerland; ${ }^{7}$ The Genomics Institute of the Novartis Research Foundation, San Diego, CA, USA and ${ }^{8}$ Australian Phenomics Facility, Canberra, ACT, Australia Correspondence: Dr CG Vinuesa, Division of Immunology and Genetics, John Curtin School of Medical Research, The Australian National University, Mills Road, PO Box 334, Canberra City, Australian Capital Territory 2601, Australia.

E-mail: carola.vinuesa@anu.edu.au
}

Received 30 June 2007; revised 30 August 2007; accepted 2 September 2007; published online 16 October 2007 
and no cells are selected to become memory B cells. TI GC B cells, like their TD counterparts, express the known germinal centre $\mathrm{B}$ cell markers PNA and GL7 and downregulate IgD. ${ }^{17}$ Despite the different fate of TD and TI GC B cells, to date, there are no markers that can differentiate phenotypically TD vs TI GC B cells. These markers are likely to prove useful tools for understanding crucial aspects of immunology, since productive GC reactions underpin all successful vaccination strategies to date, and are essential for long-lasting immunity against certain life-threatening bacteria, viruses and toxins. Furthermore, productive GC may also be the source of pathogenic autoantibodies in diseases such as systemic lupus erythematosus. ${ }^{18}$ Also, identification of the molecular signature of TD GC B cells should provide important insights into the pathways that determine GC B cell survival, selection and differentiation, which all require T-cell help.

To this end, we have compared the gene expression signature of otherwise matched populations of TD and TI GC B cells. We show that a group of genes previously known to be involved in axonal growth and provision of axon guidance cues are selectively expressed in TD GC B cells. Among these, Basp1 and Plexin B2 emerge as new markers of productive GC. Furthermore, this pattern of gene expression coincides with the development of long neurite-like projections revealed by microscopic analysis of B cell subsets.

\section{RESULTS}

\section{Selective gene expression on TD GC B cells}

To compare the gene expression profiles of productive TD GC and non-productive TI GC, QMxB6 F1 mice were immunized with (4-hydroxy-3-nitrophenyl) acetyl (NP)-Ficoll (TI antigen) or NP-chicken gamma globulin (CGG) (TD antigen) as described in the methods. The latter group ('TD D4') had been primed with CGG 5 weeks earlier so that T-cell help was not limiting. Mice immunized with both TD and TI antigens developed $\mathrm{PNA}^{+}$and GL-7 ${ }^{+}$GC B cells (Figures 1a and b) 3 days after immunization. Recirculating and GC B cells were sorted 4 days after immunization on the basis of GL-7 expression (Figure 1b). A third group of non-primed QMxB6 F1 mice were also immunized with NP-CGG, and GC B cells from these mice were sorted on day 10 , at the peak of the GC reaction during a primary response ('TD D10'). GC B cells in all three groups expressed Bcl-6 (Supplementary Figure 1). RNA was extracted, biotin-labeled and hybridized onto Affymetrix microarrays. Comparison of expression profiles from resting, TI GC and TD GC B cells identified 55 genes that were selectively upregulated (over twofold) and 25 genes that were selectively downregulated in TD GC B cells (Figures 2a and b). These differentially expressed genes are candidate mediators of GC B cell selection by $\mathrm{T}$ cells and/or B cell memory formation.

Unique axon-related gene expression signature in TD GC B cells Nine out of the 80 differentially expressed genes on TD GC B cellsPlexin B2 (Plxnb2), brain abundant membrane attached signal protein 1 (Basp1), nasal embryonic LHRH factor (Nelf), sonic hedgehog homolog $(S h h)$, T-complex protein 1 (Tcp1), sterol-C4-methyl oxidase-like (Sc4mol), sulfotransferase family 4A, member 1 (Sult4a1), ligatin (Lgtn), myristoylated alanine-rich protein kinase C substrate (Marcks) and Solute carrier family 6 (neurotransmitter transporter, GABA), member 1 (Slc6a1) (Figure 3a)-are known to be involved in the regulation of neurite (axons and dendrites) growth and guidance (Table 1). With the exception of Shh, these genes have not been previously shown to have a function in immune responses. Quantitative reverse transcription-PCR analysis confirmed increased RNA levels of Plexin B2, Basp1, Nelf, Tcp1 and Sc4mol in TD GC B cells (Figure 3b). This signature corresponds with the formation of long neurite-like structures on GC B cells. Microscopic and ultrastructural analysis of mouse and human GC B cells revealed that GC, but not resting, B cells form a small number of cytoplasmic projections (Figure 4). Cytoplasmic outgrowths that were longer than the diameter of the cell body were observed in 1-6\% of both TD and TI mouse GC B cells, but were virtually absent in resting B cells from unimmunized mice, in which only small microvilli could be seen. T-cell selection in GC is thought to operate on CC. Thus, dendrite formation by CB and CC was compared. Human $\mathrm{CC}$ and $\mathrm{CB}$ were sorted from tonsil single cell suspensions; recirculating $B$ cells were sorted from peripheral blood and examined by scanning electron microscopy. Dendrites of variable lengths were more commonly observed in CC, occasionally found in $\mathrm{CB}$ and absent in resting $B$ cells (Figures $4 \mathrm{~b}$ and $\mathrm{c}$ ). Dendrite formation has been previously reported in B cells stimulated with interleukin (IL)-4 in combination with lipopolysaccharide. ${ }^{19}$

\section{BASP1 is expressed at high levels on TD GC B cells}

BASP1 is known to promote neurite outgrowth and mediate axonal repair after axotomy. ${ }^{20}$ To confirm that BASP1 protein is expressed in TD GC B cells, C57BL/6 mice were immunized with sheep red blood cells (SRBC) and GL-7 ${ }^{\text {high }} \mathrm{Fas}^{+}$B220 $0^{+}$GC B cells were identified by fluorescence-activated cell sorting (FACS) 10 days later (Figure 5a). Polyclonal rabbit serum raised against BASP1 was used to detect intracellular BASP1 protein expression and pre-immune serum was used as the control. BASP1 was not detected in resting B cells but was expressed highly by GC B cells (Figure $5 b$ ). To confirm selective expression of BASP1 in the GC B cell subset, and assess expression on other lymphoid and myeloid subsets, immunohistochemistry was performed on spleen sections of mice 8-14 days after immunization with alum-precipitated NP-CGG plus heat-killed Bordetella pertussis. Highest expression of BASP1 was found in GC B cells, while BASP1 ${ }^{+}$ $\mathrm{B}$ cells were not found in the primary follicles (resting B cells) (Figures $5 c-e$ ). Variable numbers of cells in the $\mathrm{T}$ zone, possibly including T cells and B blasts, expressed BASP1 (Figures $5 \mathrm{c}-\mathrm{e}$ ), but here expression was heterogeneous. Consistent with the microarray results, BASP1 was expressed at much higher levels on GC from spleens of mice immunized with TD antigens compared with those immunized with TI-2 antigens (Figure 5e). Finally, lysates from sorted GC B cells and resting B cells were separated by SDSpolyacrylamide gel electrophoresis and blotted with anti-BASP1 serum. A clear single band of the expected $\operatorname{size}^{21}$ was found in GC but not resting B cells (Figure 5f).

Next, we tested whether Baspl is induced upon B cell activation in vitro. No Basp1 expression occurred after cells were activated with anti-IgM or anti-CD40 alone, but a fourfold increase in Basp1 mRNA was observed after $24 \mathrm{~h}$ when these two stimuli were combined (Figure $5 \mathrm{~g}$ ), compared with an $\sim 80$-fold increase in BASP1 expression observed in freshly isolated GC B cells over that in resting B cells (Figure 3b). This difference in expression may be explained by the fact anti-IgM plus anti-CD40 stimulation does not generate GC B cells in vitro.

\section{PLEXIN B2 is selectively and strongly expressed on GC B cells} Plexin family members are important for the detection of guidance cues that direct axon migration in the nervous system. ${ }^{22}$ One of these molecules, PLEXIN B2, is highly expressed in neurons, and mediates both attraction and repulsion reactions depending on the stimulus and type of neuron. ${ }^{23,24}$ PLEXIN B2 was not expressed in either resting or TI GC B cells, but is expressed at significant levels in TD GC (Figure 2). FACS analysis using a PLEXIN B2-specific monoclonal antibody confirmed that PLEXIN B2 protein was expressed highly on 
a
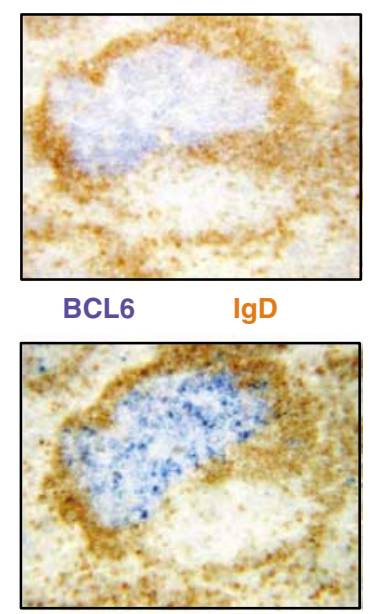

$\lg D$

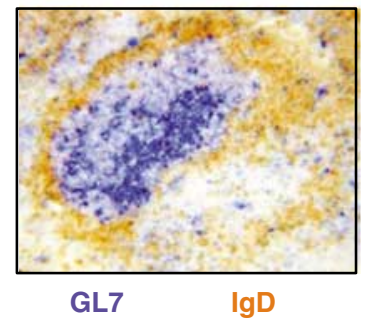

b
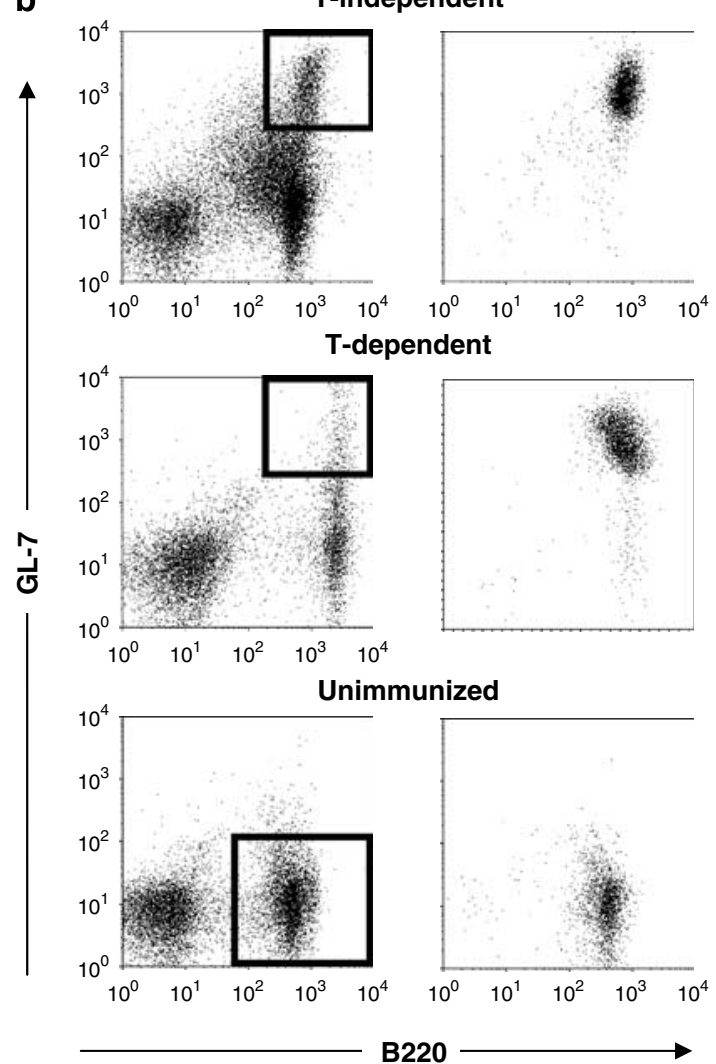

Figure 1 Strategy for sorting GC B cells. (a) PNA and GL-7 selectively stain GC B cells on consecutive frozen sections from spleens of mice immunized with NP-CGG. (b) B220+GL-7high splenocytes from mice immunized with TD or TI-2 antigen were sorted as GC B cells and B220+GL-7- splenocytes from unimmunized mice were sorted as resting B cells. GC, germinal centre; NP, (4-hydroxy-3-nitrophenyl) acetyl; CGG, chicken gamma globulin; TD, T cell-dependent; TI-2, T-independent type 2.

GC B cells and absent on resting B cells (Figure 6a). Immunohistochemical staining of spleen sections from immunized mice showed that PLEXIN B2 was confined to B cells within GC. Specific PLEXIN B2 staining could also be seen in cells scattered through the red pulp and $\mathrm{T}$ zones, suggesting that other cell types-possibly dendritic cells and/or macrophages-may also express this protein (Figure 6b). No specific PLEXIN B2 could be detected in TI GCs by immunohistochemical staining (data not shown). Finally, expression of Plexin B2 on GC B cells was also confirmed by western blotting. As with BASP1, a band of the expected size was only observed in the GC B cell lysates but not in resting B cells (Figure $6 \mathrm{c}$ ).

Besides the follicular/GC pathway of B-cell differentiation, activated B cells can also differentiate along the extrafollicular pathway to become short lived, low affinity plasma cells. Extrafollicular plasma cells form in both TD and TI B cell responses. PLEXIN B2 expression in this pathway was examined using a well-defined congenic adoptive transfer system in which CD45.2 $\mathrm{SW}_{\mathrm{HEL}} \mathrm{B}$ cells are transferred into CD45.1 recipients and immunization with SRBC conjugated with mutant HEL (hen egg lysozyme), $\mathrm{HEL}^{2 \times}$ results in extrafollicular CD45. $2^{\text {int }} \mathrm{HEL}^{\text {int }}$ Syn- $1^{+}$plasmablasts and plasma cells, and follicular/ germinal centre B cells that are CD45.2 ${ }^{\text {high }} \mathrm{HEL}{ }^{\text {high }}$ Syn- $1^{-25}$ In this model, PLEXIN B2 expression was detectable on extrafollicular plasma cells, but the levels were more than twofold lower than those found on GC B cells (Figure 6d).

To assess PLEXIN B2 expression by B cells activated in vitro, purified $B$ cells were cultured with mitogenic stimuli in the presence of IL-2. No significant induction of PLEXIN B2 was detected after $48 \mathrm{~h}$. However, after 6 days (when most B cells in the cultures have differentiated into plasmablasts and/or plasma cells), PLEXIN B2 was detected in cells stimulated under all conditions. The highest levels of PLEXIN B2 induced in culture were found on lipopolysaccharide-activated plasmablasts (Figure 6e). Nevertheless, PLEXIN B2 expression on GC B cells was still $\sim 2$-fold higher than that found in in vitro-generated plasmablasts. Taken together, these data show PLEXIN B2 is expressed selectively and highly on GC B cells although lower levels can be found on extrafollicular plasmablasts.

\section{Human GC B cells express axon growth and guidance genes}

Finally, we assessed Basp1 and Plexin B2 expression in human tonsillar GC cells (CC and CB) and memory B cells from peripheral blood $\left(\mathrm{CD} 19^{+} \mathrm{IgD}^{-} \mathrm{CD} 27^{+}\right.$cells) using gene expression data obtained by Affymetrix microarray analysis of each these B cell populations. ${ }^{15}$ Although Basp1 itself was only minimally upregulated (Supplementary Figure 2), Gap-43, a protein that is closely related functionally to Basp1 and can substitute for the latter in vivo to restore nerve sprouting, ${ }^{20}$ was upregulated in both CC and CB. Expression of Marcks, the third member of the Gap-43-like protein family, ${ }^{26}$ was downregulated in both $\mathrm{CB}$ and $\mathrm{CC}$, thus following the same trend as that seen in mouse TD, but not TI, GC. In addition, in both CB and CC, Plexin B2 expression was found to be upregulated by $\sim 4$-fold and remained $\sim 2$-fold higher in memory B cells compared to resting cells (Supplementary Figure 2). 
a
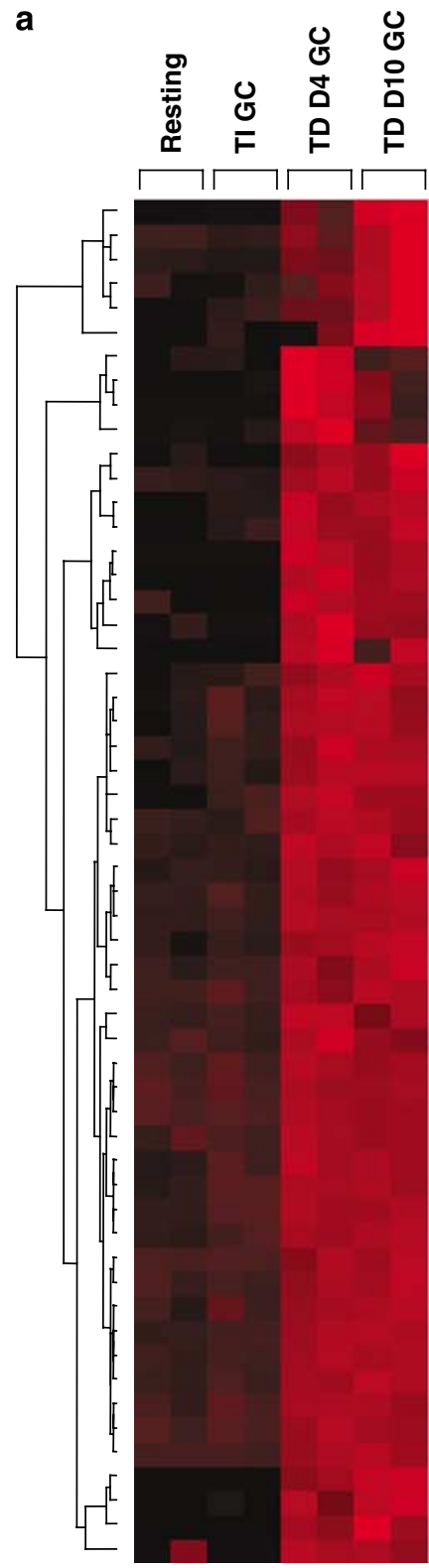

b

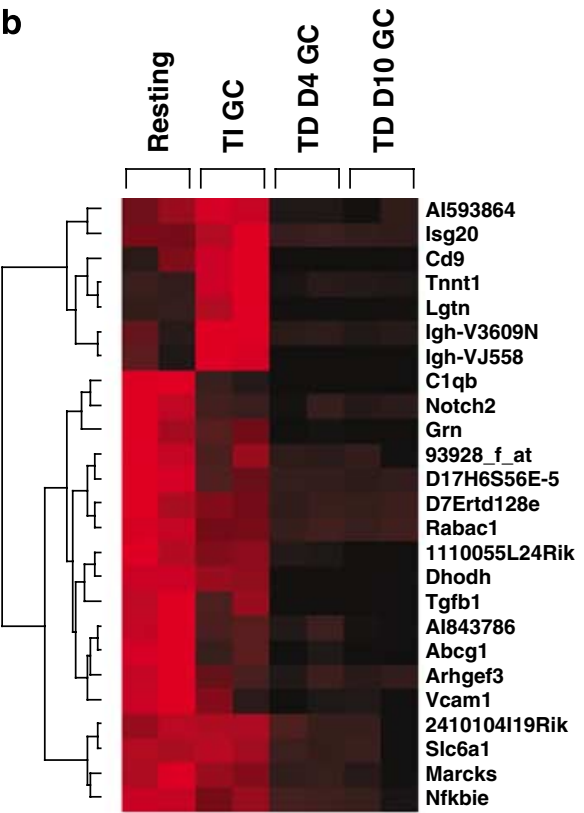

2000
Igh-3

E430007M08Rik

Ocln

Ssr3

D8Ertd69e

Ebna1bp2

Mafb

Prken

Mst1r

Slpi

Basp1

Nelf

Dhfr

1500003003Rik

Cul4a

Sult4a1

Mrps22

Hmgb1

Hspa4

Psip1

Tcp1

Timd2

Hat1

Gcet

mo7

Tmpo

Sfrs1

Gatm

Mtf2

Al324046

Cfdp

Sfpq

Usp14

Ube2d2

AA536749

Lipc
Cbx3

Cbx3

Sc4mol

161153_r_at

Mtf2

93908_f_at

Tcea1

Tcea1

1810073N04Rik

1810073

Eif2s1

Al788669

Eif3s10

Arl10c

Igh-4

Igh-4

Ube2i

Figure 2 Genes selectively regulated on TD GC B cells. Genes expressed differentially by at least twofold after analysis of variance analysis with $P<0.01$ were studied. Upregulated genes were selected using the following algorithm: present in TD4 and TD10 with expression value $>2$-fold increase above the average expression of duplicate chips in a 4-way comparison (Resting vs TD D4, Resting vs TD D10, TI vs TD D4 and TI vs TD D10). Downregulated genes were selected using the following algorithm: present in $\mathrm{R}$ and $\mathrm{TI}$ with expression value $>2$-fold increase above the average expression of duplicate chips in a 4-way comparison (Resting vs TD D4, Resting vs TD D10, TI vs TD D4 and TI vs TD D10). Selected genes were normalized and clustered using CLUSTER software and visualized using Gene Tree View software. (a) Fifty-five genes were upregulated on TD GC B cells. (b) Twenty-five genes were downregulated on TD GC B cells. TD, T cell-dependent; GC, germinal centre; TI, T-independent.

Differential expression of TD GC B cell genes in pre- and post-GC B cell neoplasms

Mature mouse B cell lineage neoplasms constitute a spectrum, ranging from pre-GC, unmutated tumours of $\lambda$-MYC transgenic mice to fully differentiated, mutated post-GC plasmacytomas (PCT). Intermediate are tumours of SJL mice that originate in greatly enlarged GCs and retain an association with the follicular white pulp while undergoing plasma cell differentiation. ${ }^{27-29}$ For each neoplasm, a cell of origin is postulated with similarities between the paired normal and malignant cells varying for each lymphoma class. The possibility that genes involved in specifying cell localization and interactions might contribute to the phenotypes of lymphomas prompted us to determine how TD GC genes might relate to tumours of known relation to GC passage. To this end, we used oligonucleotide microarrays (Figure 7) to study expression patterns of transcripts in pre-GC $\lambda$-MYC lymphomas (designated $\mathrm{BL}$ ), and post-GC SJL tumours and PCT (designated PCT).

Hierarchical clustering of the genes identified two major subsets (Figure 7), one with genes expressed at higher levels in PCT and/or SJL lymphomas, and the second with higher levels of gene expression in pre-GC lymphomas. The genes preferentially expressed in the post-GC neoplasms as opposed to pre-GC neoplasms included a number of the 

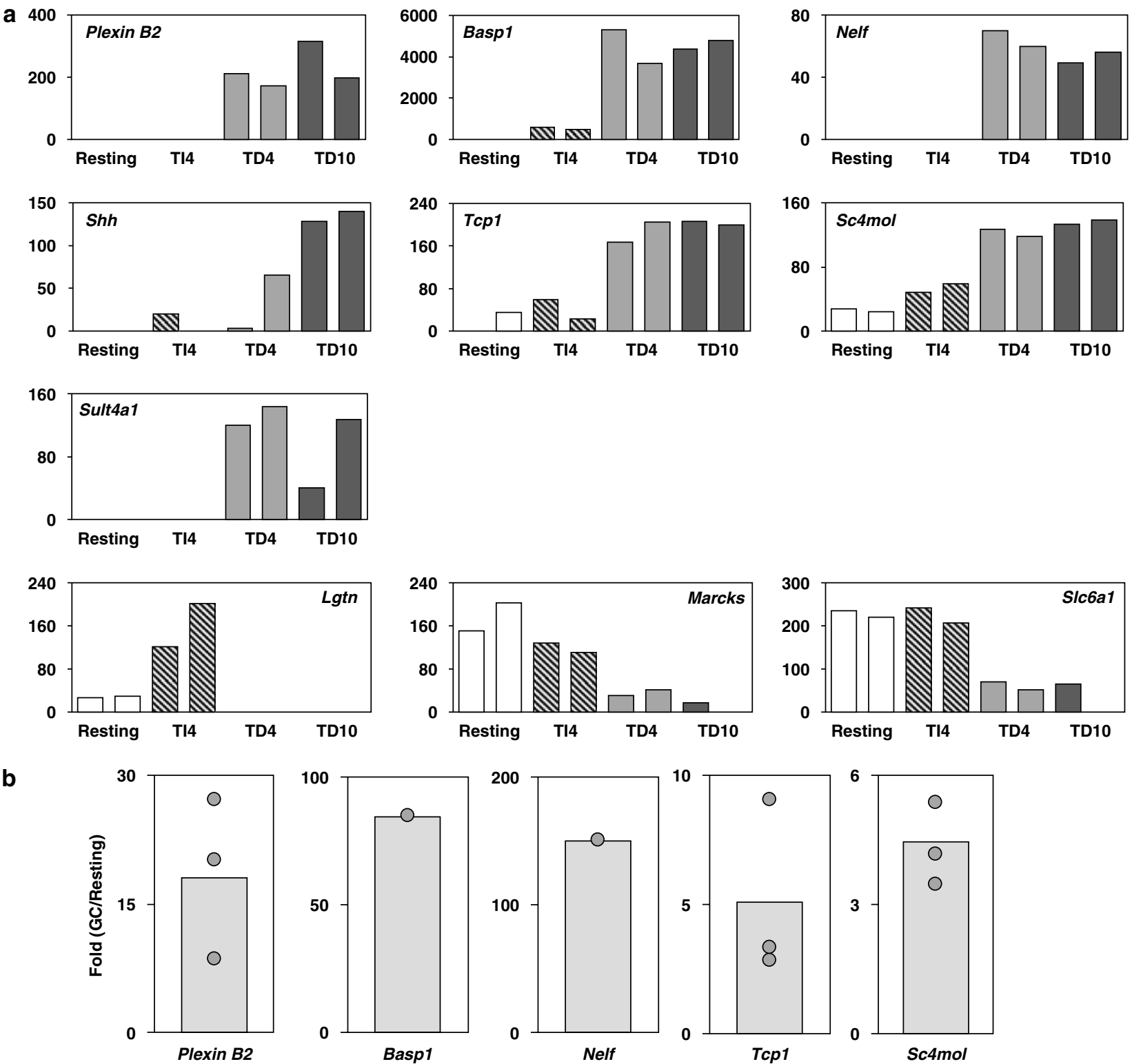

Figure 3 Expression of neurite-regulating genes by microarray and quantitative RT-PCR. (a) Signal value of selected genes by microarray analysis after normalization ( $y$ axis). (b) Quantitative RT-PCR in sorted resting and GC B cells from mice immunized by SRBC. The mRNA copy numbers were normalized by $\beta$-actin. The fold increase of GC B cells to resting B cells is shown (each dot represents an independent experiment and grey bars represent mean values). TI4, TI GC group; TD4, TD D4 GC group; TD10, TD D10 GC group. RT, reverse transcription; GC, germinal centre; SRBC, sheep red blood cells; TI, T-independent.

neuronal genes that were selectively upregulated in TD GC B cellsBasp1, Shh, Sult4a1 and Sc4mol. Plexin B2 was expressed by both types of neoplasms and expression differences were not statistically significant. Although the pre-GC neoplasms lack expression of most of the TD GC genes that are known to be involved in axon growth and guidance, they do express a number of genes that are also selectively expressed at high levels in TD GC B cells: Mtf2, Dhfr, Cbx3, Hmgb1 and Tmpo. This suggests that they may derive from what has recently been described as the GC 'founder cell' subset of AID-positive but non-mutated, non-switched cells that have already acquired some GC features. ${ }^{30}$ Interestingly, the GC marker gene, Gcet, which is also selectively expressed in TD GC B cells (Figure 2a) is 'trapped' for continuingly high expression in the SJL tumours but downregulated in the more mature PCT.

\section{DISCUSSION}

We have compared the gene expression signature from highly purified TD and TI GC B cells generated in vivo and identified 80 genes differentially expressed in productive TD GC B cells. Remarkably, this hypothesis-free survey has identified a cluster of genes expressed selectively in GC B cells receiving T-cell selection signals that were previously only known to be involved in neuronal axon growth and migration. In addition, GC B cells and notably CC appear to be distinguished from resting B cell populations by their tendency to form dendritic cytoplasmic outgrowths. This finding supports and extends the recent demonstration of GC dynamics. ${ }^{2-4}$ Differentiation of GC B cells corresponds with morphological changes that appear to be crucial for affinity maturation to take place: the molecular machinery that drives axon growth and guidance in neurons is co-opted in GC B cells. 
Table 1 Neurite growth genes differentially expressed in TD GC B cells

\begin{tabular}{|c|c|c|c|c|c|}
\hline $\begin{array}{l}\text { Gene } \\
\text { symbol }\end{array}$ & Expression pattern & Subcellular localization & Function in neurons/CNS & Other functions & References \\
\hline $\begin{array}{l}\text { Plxnb2 } \\
\text { (Plexin B2) }\end{array}$ & Developing nervous system & Cell surface & Neurite growth and guidance & Not known & $23,32,47,57$ \\
\hline Basp1 & $\begin{array}{l}\text { Adult central and peripheral nervous } \\
\text { system; early embryonic developing } \\
\text { tissues }\end{array}$ & $\begin{array}{l}\text { Plasmalemmal microdomains } \\
\text { (rafts) }\end{array}$ & $\begin{array}{l}\text { Neurite sprouting, synaptic plasiticity, } \\
\text { axon repair after axotomy, cell adhesion } \\
\text { and spreading }\end{array}$ & Not known & $20,21,42$ \\
\hline Nelf & $\begin{array}{l}\text { Embryonic developing nervous } \\
\text { system }\end{array}$ & Cell surface & $\begin{array}{l}\text { Axonal projection guidance and } \\
\text { neuronal migration }\end{array}$ & Not known & 58,59 \\
\hline Shh & $\begin{array}{l}\text { Embryonic developing nervous } \\
\text { system and limbs; adult organs }\end{array}$ & $\begin{array}{l}\text { Secreted, diffuses; endosomes } \\
\text { and lysosomes }\end{array}$ & $\begin{array}{l}\text { Axon guidance; regulation of CNS } \\
\text { polarity, neural stem cell proliferation, } \\
\text { neuronal and glial cell survival }\end{array}$ & $\begin{array}{l}\text { Regulates } \\
\text { morphology of } \\
\text { many tissues }\end{array}$ & 60,61 \\
\hline Tcp1 & Wide tissue expression & $\begin{array}{l}\text { Cytoplasm, particularly at the } \\
\text { leading edge of growth cones } \\
\text { in neuritic processes }\end{array}$ & Axonal growth & $\begin{array}{l}\text { Folding of } \\
\text { cytoskeletal } \\
\text { proteins }\end{array}$ & $62-64$ \\
\hline Sc4mol & Brain & Cytoplasm & Repair after axotomy & Not known & 65 \\
\hline Sult4a1 & Selectively in the brain & Cytoplasm & Related to schizophrenia & Not known & $66-68$ \\
\hline Marcks & Many tissues, particularly in the brain & $\begin{array}{l}\text { Plasmalemmal microdomains } \\
\text { (rafts) }\end{array}$ & Maintenance of dendritic spins & $\begin{array}{l}\text { Cellular } \\
\text { migration, } \\
\text { adhesion }\end{array}$ & 43 \\
\hline Ligatin & Mainly in the central nervous system & Cytoplasm, particularly in dendrites & Neuroplasticity, cell-cell interactions & Not known & 69 \\
\hline Scl6a1 & Neurons and glial cells in the brain & Processes and nerve endings & Neurotransmission regulation & Not known & 70 \\
\hline
\end{tabular}
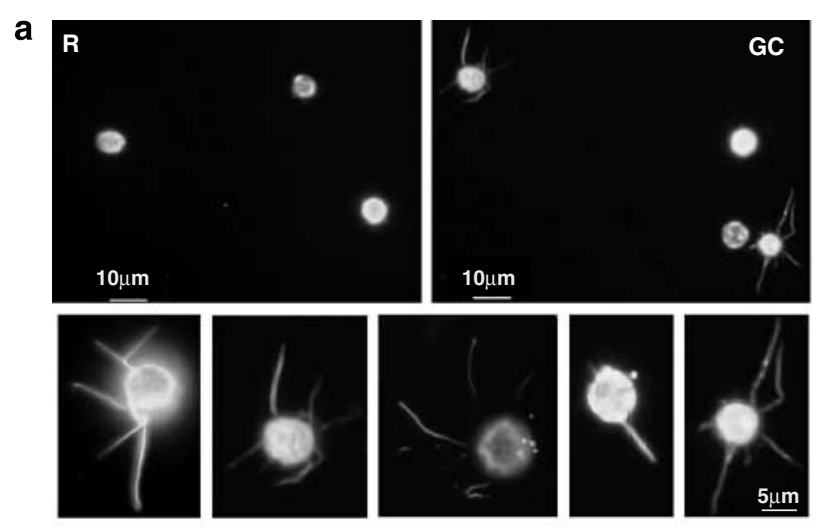

b
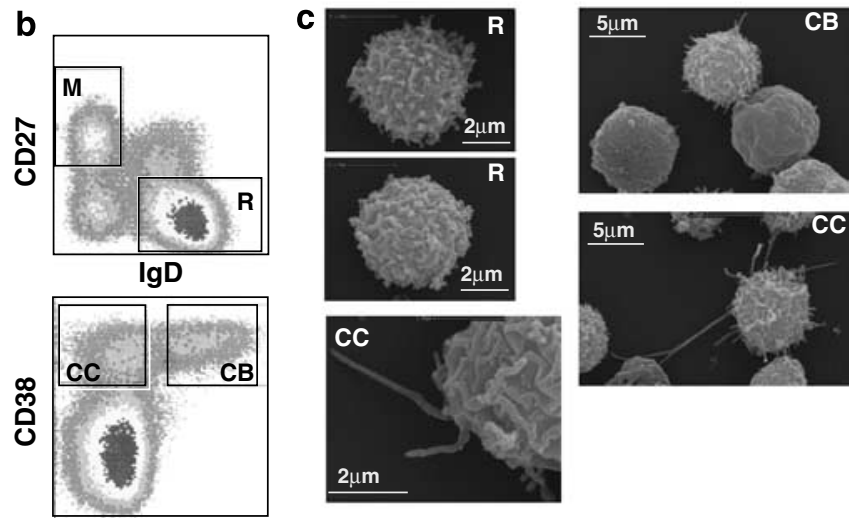

CD77

Figure 4 Morphology of resting $B$ cells and GC B cells. (a) Immunofluorescence of sorted resting (R) and GC B cells after fixing and staining with Oregon Green 488 phalloidin. (b, c) Scanning electron microscopic analysis of sorted human resting (R), centroblasts (CB) and centrocytes (CC). The strategy used for sorting $\mathrm{R}, \mathrm{CB}$ and $\mathrm{CC}$ populations is shown in (b). M, memory B cells; GC, germinal centre.
We have taken advantage of a model in which GC can be induced with highly similar kinetics and characteristics up until the point of selection and differentiation. This allows the possibility of comparing two highly homogeneous GC populations with indistinguishable phenotype but polar opposite fates. In both TD and TI GC, CC emerge 3 days after immunization, but in the subsequent $48 \mathrm{~h}$ differentiation into plasma cells and memory cells, it only occurs in GC that contain antigen-specific $\mathrm{T}$ cells. ${ }^{13}$ This in vivo model is crucial, since recapitulating GC in vitro has been problematic, probably reflecting the complex reorganization of the follicular microenvironment that takes place during immune responses and governs the cellular interactions necessary for CC selection. In vitro, B cells can be induced to become short-lived unmutated plasma cells in the presence of various mitogenic stimuli. Although Bcl-6 overexpression in B cells can induce a GC phenotype in vitro, ${ }^{31}$ studies of these cells are hampered by their limited survival in vitro. Thus the molecular mechanisms that determine terminal B cell differentiation within GC remain elusive.

After identifying a cluster of genes expressed selectively in productive GC that were previously only known for their role in axonal growth and guidance, we focused our analysis on Plexin B2 and Basp1, since the magnitude of differential expression was highly significant. PLEXIN B2 was selectively expressed in TD GC B cells and absent in both resting and TI GC B cells. BASP1 was not expressed at all by resting B cells, and was expressed only weakly on TI GC B cells, but was strongly expressed in TD GC B cells. Nelf, Shh, Tcp1, Sc4mol, Sult4a1, Lgtn, Marcks, and Slc6a1 genes previously described to participate in neurite growth and guidance were also differentially expressed in TD GC B cells.

Plexins are a highly conserved family of neuronal receptors for the axon-guiding membrane-bound semaphorins. Soluble semahorins can also signal through plexins but some of them require these to form complexes with neuropilins. Semaphorins direct axonal steering and branching by acting as chemorepellents or chemoattractants. ${ }^{22}$ 

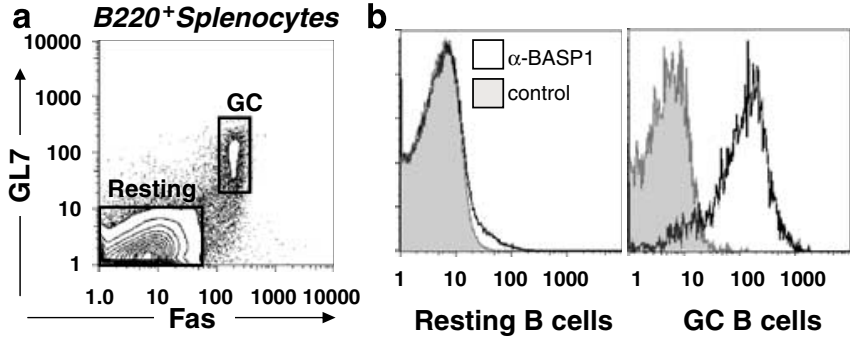

c

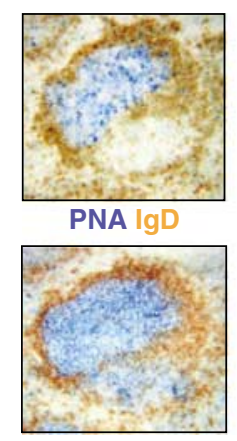

BASP1/gD

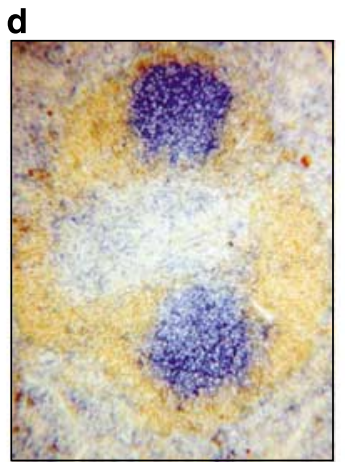

BASP1lgD

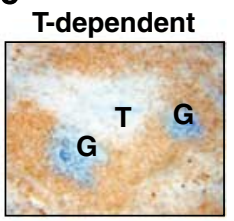

T-independent

$\mathbf{T}$

G

G

BASP1lgD f

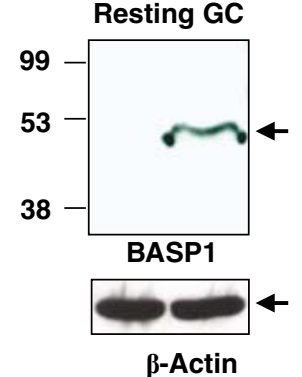

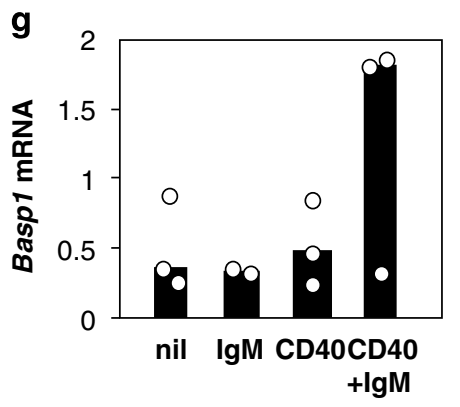

Figure 5 BASP1 is expressed by TD GC B cells. (a) Flow cytometric strategy for gating resting $B$ cells and GC B cells from mice immunized with SRBCs 8-12 days before. (b) Shaded histograms show BASP1 staining by flow cytometry on resting B cells (left) and GC B cells (right). Pre-immunized rabbit serum was used as a staining control (open histograms). (c-e) Photomicrographs of spleen sections from (QMxC57BL/6 F1) mice from the TD D4 GC group (top panel: c, d, e) or from the TI GC group stained with PNA or BASP1 in blue and IgD in brown. BASP1 selectively stains TD GC, but not TI GC. G, germinal centres; T, T zones. (f) Western blots from lysates of sorted resting B cells and GC B cells probed with anti-BASP1 serum. $\beta$-Actin was used as a loading control. (g) Real time PCR indicating relative Basp1 mRNA levels in MACS-purified $\mathrm{B}^{220^{+}}$spleen cells incubated for $24 \mathrm{~h}$ with anti-IgM, anti-CD40 or anti-IgM plus anti-CD40. TD, T celldependent; GC, germinal centre; SRBCs, sheep red blood cells; TI, T-independent; Ig, immunoglobin.

Plexin family members B1, B2 and B3 are expressed in the central nervous system during development in a non-redundant manner. ${ }^{23}$ To our knowledge, there have been no published reports of PLEXIN B2 expression in the immune system. In neurons, Semaphorin $4 \mathrm{D}$ (SEMA4D)/CD100 binds to PLEXIN B2. ${ }^{32}$ SEMA4D/CD100 is expressed on $\mathrm{T}$ cells, ${ }^{33}$ and has been found within GC. ${ }^{34}$ Sema4d/ Cd100 knockout mice have markedly reduced GC and defective affinity maturation during TD immune responses, ${ }^{35}$ whereas Sema4d/Cd100 transgenic mice display enhanced TD responses. ${ }^{36}$ CD72 has been reported to be the receptor for $\mathrm{T}$ cell-derived SEMA4D/CD100 on lymphocytes. ${ }^{37}$ Nevertheless, CD72-deficient

mice have no obvious defects in TD responses. ${ }^{38}$ It is therefore possible that PLEXIN B2 mediates the effects of SEMA4D/CD100 in affinity maturation within GC. This contention is supported by selective upregulation of macrophage stimulating 1 receptor (Mst1r)/Ron in TD GC B cells (Figure 2): both RON and hepatocyte growth factor receptor (HGFR)/MET are known to form multimeric receptor complexes with plexins to mediate SEMA4D/CD100 signaling. ${ }^{39,40}$ Furthermore, HGFR/MET is known to be expressed on human GC B cells. ${ }^{41}$

BASP1 is also important for neurite outgrowth and regulates nerve sprouting. It has been shown that BASP1 and growth associated protein 43 (GAP-43) cooperate to induce axonal regeneration after axotomy. ${ }^{20}$ BASP1 together with GAP43 and myristoylated alaninerich $C$ kinase substrate (MARCKS) are plasmalemma-associated PKC substrates and control the availability of $\mathrm{PI}(4,5) \mathrm{P}_{2}$ to regulate the actin cytoskeleton and growth of neuronal processes. ${ }^{42}$ Intriguingly, Marcks is selectively downregulated in TD GC B cells. Recent studies have shown that MARCKS regulates the stability and plasticity of dendritic spines and this is PKC-dependent. ${ }^{43}$ The non-overlapping phenotypes of Basp1- and Marcks-deficient mice suggest they play related but nonredundant roles. ${ }^{20,44}$ Nevertheless, there have been no reports of inverse regulation of BASP1 and MARCKS in the central or peripheral nervous system. The known functions of other neurite growth and guidance genes are listed in Table 1. Products of these other genes are also involved in axon initiation and growth (TCP1, SC4MOL), axon guidance (NELF, SHH) and synaptic regulation (SLC6A1, LGTN).

The selective expression of PLEXIN B2 and other neuronal outgrowth molecules on TD GC B cells and the known expression of PLEXIN B2 ligand SEMA4D/CD100 on T cells and GC, together suggest that signals through some of these 'neuronal' genes may guide dendritic cytoplasmic outgrowths on GC B cells to establish interaction with $\mathrm{T}_{\mathrm{FH}}$ cells. Microscopic analysis of highly purified GC B cells revealed long neurite-like structures (Figure $4 \mathrm{a}$ ) in both TD and TI $\mathrm{B}_{2} 20^{+} \mathrm{GL}_{-} 7^{+} \mathrm{IgD}^{-}$cells. Phalloidin staining confirmed that these are F-actin-based structures as opposed to tunneling nanotubes, which have been reported to form and facilitate intercellular communications between immune cells. ${ }^{45,46}$ In our experiments, neurite-like structures were found on only a small fraction of GC B cells ex vivo ( $\sim 1-6 \%)$. In vivo, these processes appear to be more common; ${ }^{3}$ the predilection for apoptosis of GC B cells together with manipulation of GC B cells ex vivo may compromise the maintenance of these fragile and dynamic actin-based structures. As neurite-like structures are present in TI B cells without upregulation of Basp1 nor Plexin B2, these genes are unlikely to be responsible for the formation of the processes per se, but are probably important for their growth and migration. This is consistent with the reported role of BASP1 and PLEXIN B2 in neurons. In the absence of BASP1, axon numbers in the peripheral nerves are normal but the nerve terminals display abnormalities suggestive of synapse instability and there is defective ultraterminal nerve sprouting. ${ }^{20}$ In the case of PLEXIN B2 deficiency, the regulation of migration of cerebellar granule cells is impaired, and the critical defect appears to lie in the orchestration of three processes: exit from cell cycle, differentiation and migration. ${ }^{47}$

Neurite-like structures guided by $\mathrm{T}$ cell-derived cues appear attractive and efficient strategies to direct CC migration and enable establishment of probing interactions with $\mathrm{T}_{\mathrm{FH}}$ cells before forming the stable cognate CC: $\mathrm{T}_{\mathrm{FH}}$ cell interaction required for $\mathrm{CC}$ selection. Long-lasting, stable T-B interactions in GC are rare; instead, GC $\mathrm{B}$ cells and T cells form multiple short-lived interactions. ${ }^{3}$ Neurite-like extensions may also contribute to CC's capacity to bind many T cells, which are limiting, within the GC. It has been shown recently that in 

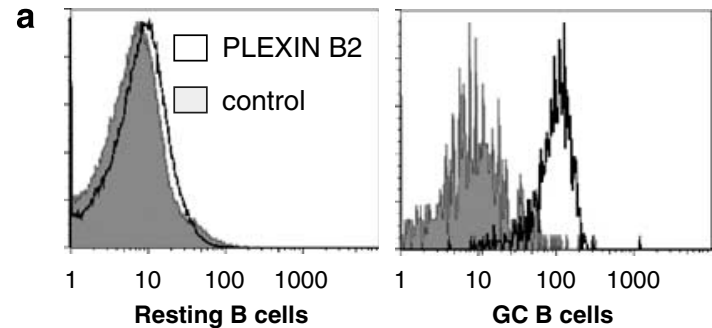

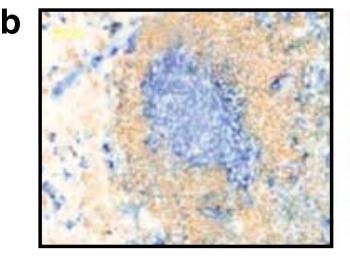

PNA IgD

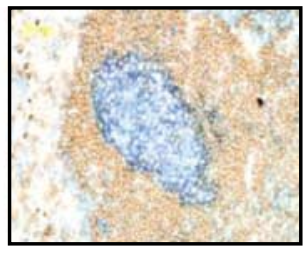

PLEXIN B2 IgD
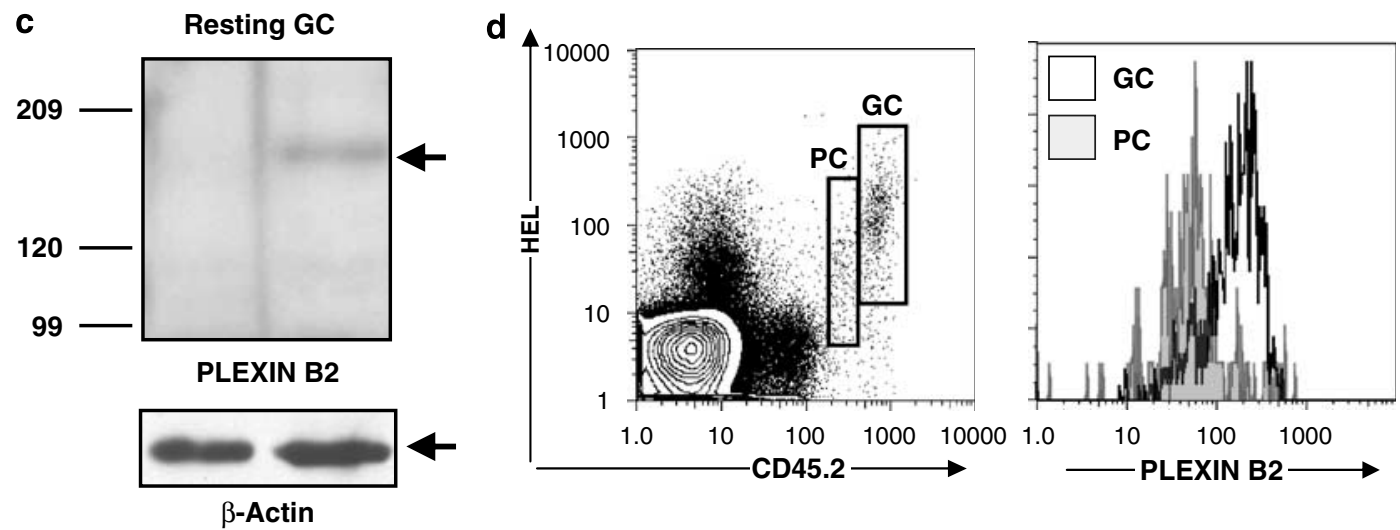

e
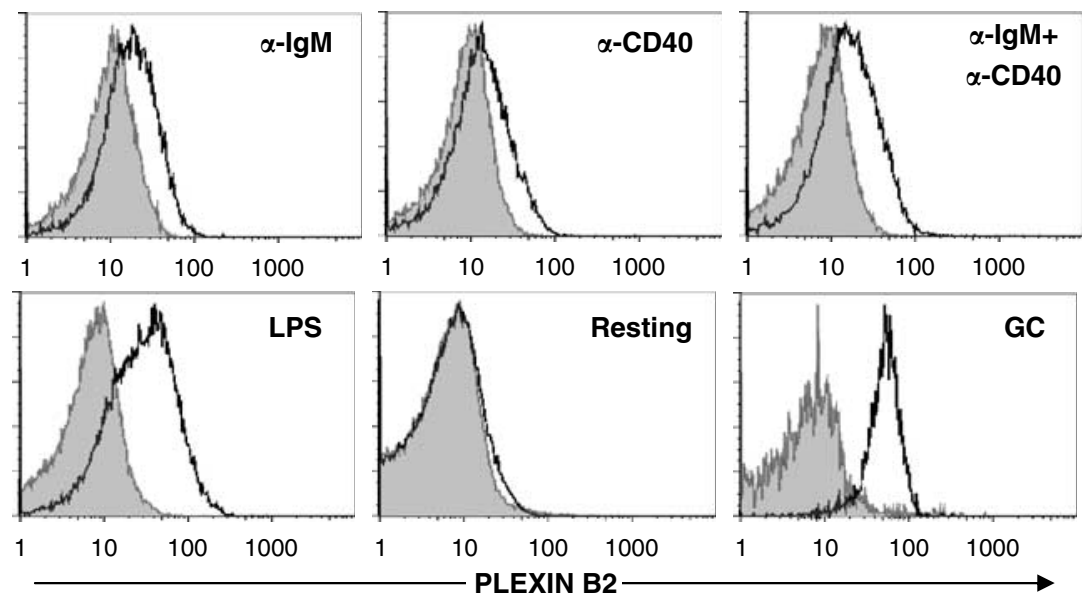

Figure 6 PLEXIN B2 is expressed by GC B cells. (a) Flow cytometric analysis of PLEXIN B2 expression (open histograms) or isotype control (shaded histograms) on splenocytes from immunized mice gated on resting B cells (top panel) and GC B cells (bottom panel) following the strategy shown in Figure 5a. (b) Photomicrographs of serial spleen sections from immunized mice showing GC stained in blue for PNA (top) and PLEXIN B2 (bottom), and in brown for IgD. (c) Western blots from lysates of sorted resting B cells and GC B cells probed with anti-PLEXIN B2 serum. $\beta$-Actin was used as a loading control. (d) Flow cytometric analysis of PLEXIN B2 expression on splenocytes from SW HEL mice 5 days after adoptive transfer into congenic CD45.1 mice and immunization with $\mathrm{HEL}^{2 \times}$-SRBC. Gates for extrafollicular CD45.2 $2^{\text {low }} \mathrm{HEL}$-binding plasma cells $(\mathrm{PC})$ and $\mathrm{CD} 45.2^{\text {high }} \mathrm{HEL}$-binding GC B cells are shown in the dot blot (left). (e) Histograms show flow cytometric analysis of PLEXIN B2 expression after stimulation of purified B cells for 6 days under the conditions indicated. The expression of PLEXIN B2 on resting B and GC cells was examined in the same experiment. Shaded histograms indicate staining with an isotype control antibody. These results are representative from at least two independent experiments. GC, germinal centre; Ig, immunoglobin; HEL, hen egg lysozyme; SRBC, sheep red blood cells.

the presence of limiting amounts of membrane-bound antigen, the process of B cell spreading can magnify differences in BCR affinity. ${ }^{48}$ $\mathrm{T}_{\mathrm{FH}}$-dependent induction of genes that promote neurite growth in $\mathrm{CC}$ may enhance this spreading mechanism, providing a way to magnify further differences in BCR affinity in a way that is guided and proofread by $\mathrm{T}_{\mathrm{FH}}$ specificity. This would result in a further increase in avidity and favour selection of high affinity mutants particularly as the amounts of antigen displayed by follicular dendritic cells becomes low at later time after immunization or infection.

Our findings suggest neurons and GC B cells share a set of neurite growth genes. There are numerous examples where certain proteins or signaling pathways are shared between very different cells types to perform related functions including cell growth, survival, adhesion, and so on. Even signaling pathways regulating very specialized functions in one system can be used by another system to achieve similar outcomes. For example, molecules like neuropilin-1 known to be involved in synapse formation in the central nervous system have also been shown to participate in immunological synapses between $\mathrm{T}$ cells and antigen-presenting cells. ${ }^{49}$ Also, common mechanisms of nerve and blood vessel wiring have been reported: a number of molecules that provide axon guidance cues or terminal arborization signals in neurons to direct neuronal cell migration and axon/dendrite growth 


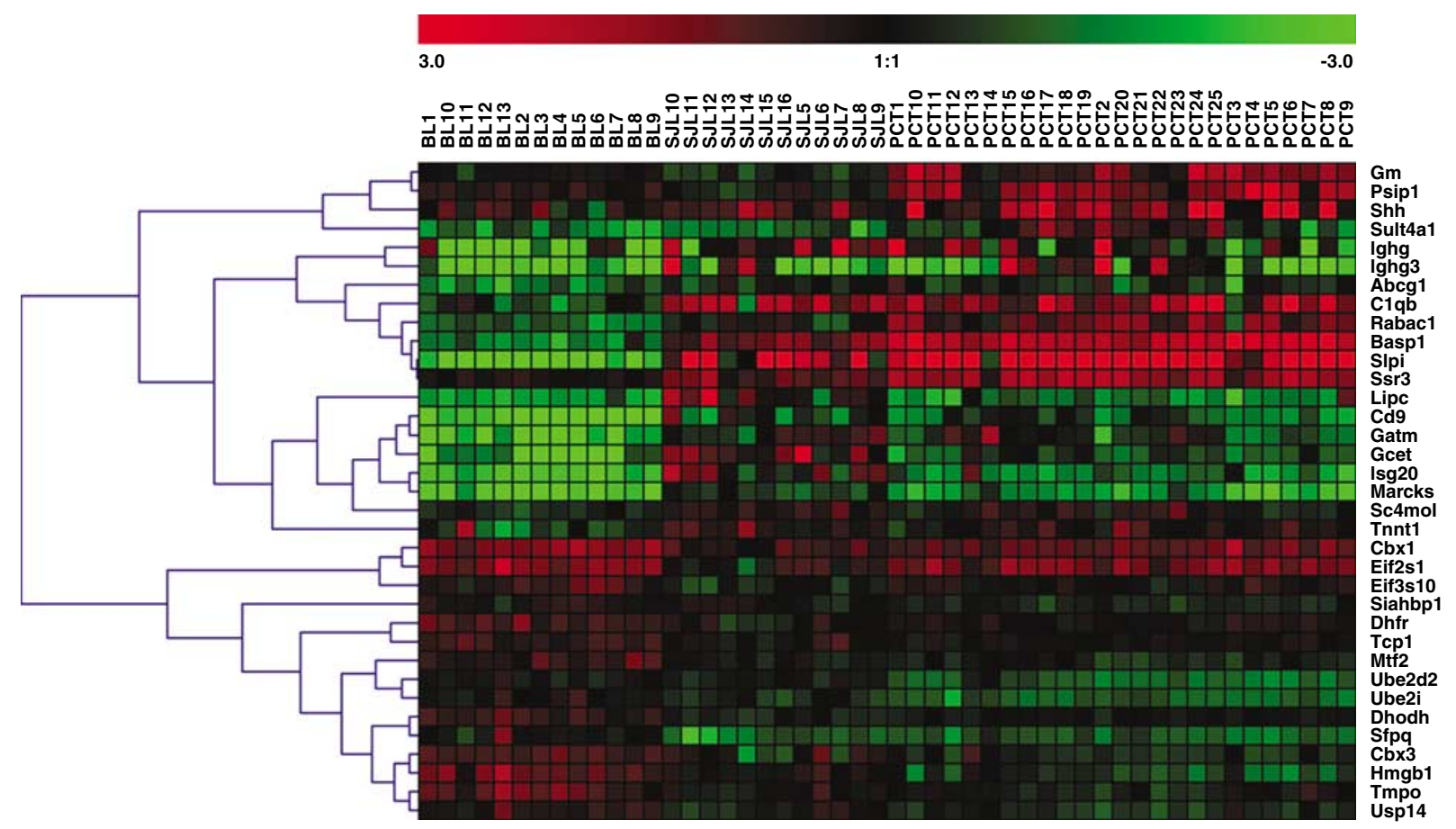

Figure 7 Expression of axon growth genes by mouse post-GC neoplasms. Hierarchical clustering of the genes shown in Figure 2, according to their differential expression in pre-GC neoplasms of $\lambda$-MYC transgenic mice (BL) and post-GC neoplasms: plasmacytomas (PCT) and the less mature post GC plasma cell neoplasms of SJL mice (SJL). The genes have been selected by $t$-test, $P<0.01$. GC, germinal centre.

have also been found expressed in blood vessels, where they direct angiogenic sprouting..$^{50}$ Furthermore, recent reports suggest that this neurite growth and guidance machinery is not only shared by the nervous and immune systems, axonal guidance proteins and their signaling partners have also been identified in the developing mouse mammary gland where they appear to influence ductal growth and morphogenesis. ${ }^{51}$ Strikingly, both BASP1 and PLEXIN B2 appear to participate in this process.

We have shown that some of these neurite growth genes, including Basp1, are also highly expressed in mouse post-GC B cell lymphomas. This is consistent with other evidence that B-cell malignancies share many features with their normal counterparts during normal antigendriven $\mathrm{B}$ cell differentiation and maturation. Interestingly, the neuronal signature was only found in tumours of clear-cut post-GC origin. By contrast, other GC-related genes were expressed in cells that could be the counterparts of GC founder cells, suggesting that the neuronal signature is a sign of late GC B-cell differentiation. This signature may be of value in future studies of mouse models of lymphoma, where classification by surface phenotyping is more difficult than in human lymphoma.

This work provides the markers to identify productive GC and possibly post-GC B cell malignancies. Further studies on the functions of the individual genes that comprise the axon growth and guidance signature of TD GC B cells will illuminate the molecular mechanisms that govern $\mathrm{T}: \mathrm{B}$ cell interactions within GCs, affinity maturation and B cell memory formation.

\section{METHODS}

Mice and immunization

QM mice carry a recombined VDJ transgene knocked into the IgH chain locus that encodes a heavy chain that when combined with any $\lambda$ light chain binds NP with high affinity. ${ }^{52}$ In QMxB6 $F_{1}$ mice $\sim 20 \%$ of B cells bind NP with high affinity. $\mathrm{SW}_{\mathrm{HEL}}$ mice have a knocked-in VDJ region in the IgH chain locus that in combination with a transgene-encoded light chain binds HEL with high affinity. ${ }^{53} \mathrm{SW}_{\mathrm{HEL}} \mathrm{B}$ cells can switch to all Ig isotypes. All mice were housed in specific pathogen-free conditions and all animal procedures were approved by the Australian National University Animal Ethics and Experimentation Committee.

To generate TI-2 and TD GC responses for microarray analysis, three groups of QMxB6 F1 mice were immunized i.p. using the following strategy: (1) 'TI group'-mice were immunized with $30 \mu \mathrm{g}$ of the model TI-2 antigen NP conjugated to Ficoll; (2) 'TD D4 group'-to generate TD GC responses with comparable kinetics to the TI group, QMxB6 F1 mice were primed with $50 \mu \mathrm{g}$ alum-precipitated CGG and then rechallenged 5 weeks later with $50 \mu \mathrm{g}$ of soluble NP-CGG so that T-cell help was not limiting. These mice were analysed on day 4 after the rechallenge. (3) 'TD D10 group'-to examine the peak of a primary TD GC reaction, mice were immunized with $50 \mu \mathrm{g}$ of alum-precipitated NP-CGG plus $1 \times 10^{9}$ heat-killed $B$. pertussis. Where indicated, TD responses and GC reactions were generated by i.p. immunization of 8- to 14-week old C57BL/6 mice with $2 \times 10^{9}$ SRBC. For experiments involving $\mathrm{SW}_{\mathrm{HEL}}$ mice, $1 \times 10^{4} \mathrm{SW}_{\mathrm{HEL}} \mathrm{B}$ cells were transferred into CD45.1 congenic C57BL/6 recipients, which were immunized i.v. with $2 \times 10^{8}$ SRBC conjugated with mutant HEL, HEL $2 \times 25$.

\section{Antibodies}

Anti-BASP1 rabbit serum was produced at Pico Caroni's laboratory. AntiPLEXIN B2 serum was made by immunizing rabbits with a PLEXIN B2 peptide conjugated to ovalbumin (NeoMPS). Monoclonal hamster antiPLEXIN B2 antibody was produced at Wendy L Havran's laboratory. Antibodies for flow cytometry were from BD Pharmingen (San Diego, CA, USA) except where otherwise indicated: anti-mouse B220-PE, B220-APC, CD11bbiotin, CD43-biotin, CD45.2-FITC, Fas-PE, GL-7-FITC and Ter119-biotin; anti-human CD19-biotin, CD27-PE, CD38-PE, IgD-FITC, purified CD77 (Serotec, Oxford, UK). For immunohistochemistry, the following antibodies were used: rat anti-mouse IgD (Southern Biotech, Birmingham, AL, USA), goat anti-mouse IgD, PNA-biotin (Vector Laboratories, Burlingame, CA, 
USA), hamster anti-PLEXIN B2, rabbit anti-BASP1, rat anti-BCL-6 (Santa Cruz, Santa Cruz, CA, USA) and rat anti-GL-7 (BD Pharmingen). Secondary antibodies used were rabbit anti-rat horseradish peroxidase (Dako, Glostrup, Denmark), goat anti-hamster-biotin (Jackson Immunoresearch, West Grove, PA, USA), goat anti-rat horseradish peroxidase (Jackson Immunoresearch) and swine anti-rabbit-biotin (Dako).

\section{Cell isolation, culture and stimulation}

In order to isolate resting and GC B cells for western blotting, single-cell suspensions were prepared from spleens of unimmunized and immunized mice, respectively, and stained with B220-PE and GL-7-FITC. Spleen cell suspensions from immunized mice were enriched for GC B cells by magnetic cell sorting with anti-FITC-magnetic beads and MACS LS columns (Miltenyi Biotec, Bergich Gladbach, Germany) according to the manufacturer's instructions. GC B cells (B220 GL-7 $\left.^{\text {high }}\right)$ and resting B cells $\left(\mathrm{B} 220^{+} \mathrm{GL}^{-} 7^{-}\right)$were sorted to $>95 \%$ purity on the FACS sorter (BD Vantage DiVa, San Jose, CA, USA). For microscopy, antibody-labeled cells were directly purified by FACS sorting without the magnetic enrichment to avoid damage of fine membrane structures. Human resting B cells $\left(\mathrm{CD} 19^{+} \mathrm{IgD}^{+} \mathrm{CD} 27^{-}\right)$were isolated by FACS sorting from peripheral blood, and $\mathrm{CB}\left(\mathrm{CD} 19^{+} \mathrm{CD} 38^{\text {hi }} \mathrm{CD} 77^{+}\right)$and $\mathrm{CC}$ $\left(\mathrm{CD} 19^{+} \mathrm{CD} 38^{\mathrm{hi}} \mathrm{CD} 77^{+}\right)$were isolated by FACS sorting from tonsils.

For in vitro stimulation assays, single cell suspensions were prepared from red blood cell-depleted splenocytes of unimmunized C57BL/6 mice and stained with biotinylated CD43, Ter119 and CD11b. Resting B cells were negatively selected by magnetic cell sorting with streptavidin magnetic beads and MACS LD columns (Miltenyi Biotec) following the manufacturer's instructions. Purity of sorted cells exceeded $95 \%$ by FACS. Purified resting B cells were cultured in RPMI media (JRH Bioscience) supplemented with 10\% FCS, 10 mм HEPES, $55 \mu \mathrm{M} \beta$-mercaptoethanol, $2 \mathrm{~mm}$ L-glutamine, $50 \mathrm{U} \mathrm{ml}^{-1}$ penicillin, $50 \mu \mathrm{g} \mathrm{ml}^{-1}$ streptomycin, $1 \mathrm{~mm}$ sodium pyruvate, and $0.1 \mathrm{~mm}$ non-essential amino acids (all from GIBCO) at $37^{\circ} \mathrm{C}$ in a $5 \% \mathrm{CO}_{2}$-humidified incubator. Goat anti-IgM $\mathrm{F}(\mathrm{ab})_{2}\left(10 \mu \mathrm{g} \mathrm{ml}^{-1}\right.$, Jackson ImmunoResearch), anti-CD40 $\left(10 \mu \mathrm{g} \mathrm{ml}^{-1}\right.$, clone 1C10), lipopolysaccharide ( $20 \mu \mathrm{g} \mathrm{ml}^{-1}$; Fluka, Seelze, Germany) and recombinant IL-4 were used for stimulation and proliferation assays.

\section{GC gene expression analysis}

Mouse resting B cells, day 4 TI GC B cells, day 4 and day 10 TD GC B cells were isolated as described above. Human GC B cells were sorted from tonsils, whereas resting and memory B cells were sorted from peripheral blood. RNA was extracted from pellets of sorted cells by RNAzol (Biogenesis, Poole, UK) treatment. Total RNA was transcribed in vitro and biotin-labeled according to the recommended Affymetrix protocol, then hybridized on Affymetrix U74A arrays in the case of mouse cells, or U95A arrays in the case of human cells. Genes were considered differentially expressed when levels differed by at least twofold after analysis of variance analysis with $P<0.01$. Microarray data comparing resting, TD day 4, TD day 10 and TI GC B cell profiles have been deposited in GEO (http://www.ncbi.nlm.nih.gov/geo/) under accession number GSE8906.

\section{Lymphomas and oligonucleotide microarrays}

NFS. $V^{+}$mice, ${ }^{54}$ SJL mice, B6. $\mathrm{MYC}^{27}$ and IL-6 transgenic mice ${ }^{27}$ were observed for development of tumours and necropsied. Samples were collected for histology and later preparation of RNA and DNA. Lymphomas were classified using a consensus nomenclature. ${ }^{55}$ Pre-GC tumours $\left(\mathrm{IgM}^{+} \mathrm{IgD}^{+}\right.$

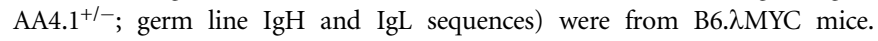
Post-GC tumours included plasma cell-rich tumours of SJL mice and PCT from IL-6 transgenic and $M y c^{H i s}$ insertion mice. ${ }^{29,56}$ RNA prepared from the samples was used to probe 70-mer oligonucleotide arrays as described. ${ }^{28} \mathrm{After}$ normalization with an R-package LIMMA (www.r-project.org; bioinf.wehi. edu.au/limma/), Student's $t$-tests were conducted to identify differentially expressed genes between pre- and post-GC neoplasms.

\section{Quantitative reverse transcription-PCR analysis}

Total RNA was prepared from purified resting and GC B cells using TRIzol (Invitrogen, Carlsbad, CA, USA) and reverse-transcribed with oligo(dT). Quantitative reverse transcription-PCR was performed using the ABI Prism
7700 sequence detection system and TaqMan Syber-green reagents (PE Biosystems, Foster City, CA, USA). Primer sequences are available on request. Fluorescence signals were measured over 40 PCR cycles and the cycle $\left(C_{t}\right)$ at which signals crossed a threshold set within the logarithmic phase was recorded. The $C_{\mathrm{t}}$ for the target gene was subtracted from the $C_{\mathrm{t}}$ for $\beta$-actin $\left(\Delta C_{\mathrm{t}}\right)$. The relative amount of mRNA was calculated as $2^{-\Delta C_{\mathrm{t}}}$.

\section{Flow cytometry}

Spleen cell suspensions were prepared by sieving and gentle pipetting. For surface staining, cells were maintained in the dark at $4{ }^{\circ} \mathrm{C}$ throughout. Cells were washed twice in ice-cold FACS buffer ( $2 \%$ fetal calf serum, $0.1 \% \mathrm{NaN}_{3}$ in PBS), then incubated with each antibody and conjugate layer for $30 \mathrm{~min}$ and washed thoroughly with FACS buffer between each layer. Intracellular staining used Cytofix/Cytoperm kit (BD Biosciences) following the manufacturer's instructions. For detection of HEL-binding B cells, HEL was conjugated to Alexa 647 (Molecular Probes, Eugene, OR, USA).

\section{Immunohistochemistry}

Frozen sections of spleen were air-dried and washed in $0.1 \mathrm{~m}$ Tris-buffered saline $(\mathrm{pH}$ 7.6) and then primary antibodies were added in Tris-buffered saline and incubated for $45 \mathrm{~min}$. After a further wash in Tris-buffered saline, secondary reagents that had been previously absorbed in $10 \%$ normal mouse serum were added to the sections for $45 \mathrm{~min}$. When biotin-conjugated primary or secondary reagents were used, streptavidin alkaline phosphatase (Vector Laboratories) was added after a further wash in Tris-buffered saline and incubated for $20 \mathrm{~min}$. Horseradish peroxidase activity was detected using diaminobenzidine tetrahydrochloride solution (Sigma, St Louis, MO, USA) and hydrogen peroxide. Alkaline phosphatase activity was detected using the AP-Substrate kit III (SK-5300, Vector Laboratories).

\section{Western blotting}

Isolated resting and GC B cells were lysed on ice in $20 \mu$ lysis buffer per $2 \times 10^{6}$ cells ( $50 \mathrm{~mm}$ Tris-base, $\mathrm{pH} 8.0,150 \mathrm{~mm} \mathrm{NaCl}, 1 \% \mathrm{NP}-40$ plus protease inhibitor (Roche, Basel, Switzerland)). The lysates were centrifuged at 13000 r.p.m., and the supernatants removed and boiled in $5 \times$ SDS sample buffer ( $10 \%$ SDS, $50 \%$ glycerol, $0.2 \mathrm{M}$ Tris-HCl, $\mathrm{pH}$ 6.8, 5\% 2-mercaptoethanol and bromophenol blue to color). Protein samples from $2 \times 10^{6}$ cells were separated on 10 or $12.5 \%$ SDS-polyacrylamide gel electrophoresis, transferred to a nitrocellulose membrane and then blotted with anti-PLEXIN B2, anti- BASP1 or unimmunized rabbit sera. Monoclonal anti-actin antibody (Sigma) was used as the loading control.

\section{Morphological studies by microscopy}

Sorted resting $\left(\mathrm{B}_{2} 20^{+} \mathrm{IgD}^{\text {high }} \mathrm{GL}-7^{-}\right)$or GC B cells $\left(\mathrm{B} 220^{+} \mathrm{IgD}^{-} \mathrm{GL}-7^{+}\right)$from mice 8-10 days after immunization with SRBC were allowed to settle onto poly-L-lysine-coated coverslips in cell culture media for $2 \mathrm{~h}$ and fixed in $2 \%$ paraformaldehyde. After one wash in PBS, cells were stained with Oregon Green 488 phalloidin (Molecular Probes) in the dark. After two further washes in PBS, the coverslips were mounted on slides with fluorescent mounting medium (Dako). The slides were observed at room temperature under an Olympus IX81 fluorescent microscope using an Olympus $60 \times$ oil (N.A. 1.42) or $100 \times$ oil (N.A. 1.35) PlanApo objective. Images were collected with an Olympus DP70 camera using software DP Controller (Version 1.2.1.108, Olympus). When necessary, the contrast of the pictures was adjusted. For scanning electron microscopy, cells were attached to Thermanix plastic coverslips coated with $0.1 \%$ poly-L-lysine. Cells were fixed in $2 \%$ glutaraldehyde in $0.1 \mathrm{~m}$ sodium cacodylate buffer ( $\mathrm{pH}$ 7.4) for $2 \mathrm{~h}$, washed three times in $0.1 \mathrm{M}$ sodium cacodylate buffer and post fixed in $1 \% \mathrm{OsO}_{4}$ in $0.1 \mathrm{M}$ sodium cacodylate buffer for $20 \mathrm{~min}$. After two further washes, the samples were dehydrated in a graded acetone series to $100 \%$ acetone and then 'critical point dried'. The samples were sputter coated with gold and photographed in a Cambridge S360 scanning electron microscope.

\section{ABBREVIATIONS}

CB, centroblast; CC, centrocytes; GC, germinal centre; HEL, hen egg lysozyme; NP, (4-hydroxy-3-nitrophenyl) acetyl; PCT, plasmacytomas; SRBC, sheep red 
blood cells; TD, T cell-dependent; TFH, follicular helper T cell; TI, T-independent; TI-2, T-independent type 2

\section{ACKNOWLEDGEMENTS}

We thank Robert Brink, Tri Giang Phan and Didrik Paus for their help with the experiments using $\mathrm{SW}_{\mathrm{HEL}}$ mice; the Biomolecular Resource Facility founded by Australian Cancer Research Foundation for the instrumental and technical support with quantitative RT-PCR; Cathy Gillespie for microscopy; David Tarlinton and Roland Friedel for helpful discussions regarding the function of PLEXIN B2. This work was supported by a Wellcome Trust International Prize Travelling Research Fellowship to CGV, NHMRC project grants 224264 and 366771 and NHMRC program grant 427620 to CCG and CVG, and the Intramural Research Program of the NIH, National Institute of Allergy and Infectious Diseases (HCM).

1 MacLennan IC, Toellner KM, Cunningham AF, Serre K, Sze DM, Zuniga E et al. Extrafollicular antibody responses. Immunol Rev 2003; 194: 8-18.

2 Schwickert TA, Lindquist RL, Shakhar G, Livshits G, Skokos D, Kosco-Vilbois MH et al. In vivo imaging of germinal centres reveals a dynamic open structure. Nature 2007; 446: 83-87.

3 Allen CD, Okada T, Tang HL, Cyster JG. Imaging of germinal center selection events during affinity maturation. Science 2006; 315: 528-531.

4 Hauser AE, Junt T, Mempel TR, Sneddon MW, Kleinstein SH, Henrickson SE et al. Definition of germinal-center $B$ cell migration in vivo reveals predominant intrazonal circulation patterns. Immunity 2007; 26: 655-667.

5 MacLennan IC. Germinal centers. Annu Rev Immunol 1994; 12: 117-139.

6 Batista FD, Neuberger MS. Affinity dependence of the B cell response to antigen: threshold, a ceiling, and the importance of off-rate. Immunity 1998; 8: 751-759.

7 Takahashi Y, Cerasoli DM, Dal Porto JM, Shimoda M, Freund R, Fang W et al. Relaxed negative selection in germinal centers and impaired affinity maturation in bcl-xL transgenic mice. J Exp Med 1999; 190: 399-410.

8 Shih TA, Meffre E, Roederer M, Nussenzweig MC. Role of BCR affinity in T cell dependent antibody responses in vivo. Nat Immunol 2002; 3: 570-575.

9 Dal Porto JM, Haberman AM, Kelsoe G, Shlomchik MJ. Very low affinity B cells form germinal centers, become memory $B$ cells, and participate in secondary immune responses when higher affinity competition is reduced. J Exp Med 2002; 195: 1215-1221.

10 Han S, Zheng B, Dal Porto J, Kelsoe G. In situ studies of the primary immune response to (4-hydroxy-3-nitrophenyl)acetyl. IV. Affinity-dependent, antigen-driven B cell apoptosis in germinal centers as a mechanism for maintaining self-tolerance. J Exp Med 1995; 182: 1635-1644.

11 Pulendran B, Kannourakis G, Nouri S, Smith KG, Nossal GJ. Soluble antigen can cause enhanced apoptosis of germinal-centre B cells. Nature 1995; 375: 331-334.

12 Shokat KM, Goodnow CC. Antigen-induced B-cell death and elimination during germinal-centre immune responses. Nature 1995; 375: 334-338.

13 de Vinuesa CG, Cook MC, Ball J, Drew M, Sunners Y, Cascalho M et al. Germinal centers without T cells. J Exp Med 2000; 191: 485-494.

14 Lentz VM, Manser T. Cutting edge: germinal centers can be induced in the absence of T cells. J Immunol 2001; 167: 15-20.

15 Gaspal FM, McConnell FM, Kim MY, Gray D, Kosco-Vilbois MH, Raykundalia CR et al. The generation of thymus-independent germinal centers depends on CD40 but not on CD154, the T cell-derived CD40-ligand. Eur J Immunol 2006; 36: 1665-1673.

16 Toellner KM, Jenkinson WE, Taylor DR, Khan M, Sze DM, Sansom DM et al. Low-leve hypermutation in T cell-independent germinal centers compared with high mutation rates associated with T cell-dependent germinal centers. J Exp Med 2002; 195 383-389.

17 Vinuesa CG, Cook MC, Cooke MP, Maclennan IC, Goodnow CC. Analysis of B cell memory formation using DNA microarrays. Ann NY Acad Sci 2002; 975: 33-45.

18 Vinuesa CG, Cook MC, Angelucci C, Athanasopoulos V, Rui L, Hill KM et al. A RINGtype ubiquitin ligase family member required to repress follicular helper $\mathrm{T}$ cells and autoimmunity. Nature 2005; 435: 452-458.

19 Davey EJ, Thyberg J, Conrad DH, Severinson E. Regulation of cell morphology in B lymphocytes by IL-4: evidence for induced cytoskeletal changes. J Immunol 1998; 160: $5366-5373$

20 Frey D, Laux T, Xu L, Schneider C, Caroni P. Shared and unique roles of CAP23 and GAP43 in actin regulation, neurite outgrowth, and anatomical plasticity. J Cell Biol 2000; 149: 1443-1454.

21 Widmer F, Caroni P. Identification, localization, and primary structure of CAP-23, a particle-bound cytosolic protein of early development. J Cell Biol 1990; 111: 3035-3047.

22 Tamagnone L, Artigiani S, Chen $\mathrm{H}, \mathrm{He} \mathrm{Z}$, Ming GI, Song $\mathrm{H}$ et al. Plexins are a large family of receptors for transmembrane, secreted, and GPI-anchored semaphorins in vertebrates. Cell 1999; 99: 71-80.

23 Worzfeld T, Puschel AW, Offermanns S, Kuner R. Plexin-B family members demonstrate non-redundant expression patterns in the developing mouse nervous system: an anatomical basis for morphogenetic effects of Sema4D during development. Eur J Neurosci 2004; 19: 2622-2632.

24 Perrot V, Vazquez-Prado J, Gutkind JS. Plexin B regulates Rho through the guanine nucleotide exchange factors leukemia-associated Rho GEF (LARG) and PDZ-RhoGEF. J Biol Chem 2002; 277: 43115-43120.

25 Paus D, Phan TG, Chan TD, Gardam S, Basten A, Brink R. Antigen recognition strength regulates the choice between extrafollicular plasma cell and germinal center $B$ cell differentiation. J Exp Med 2006; 203: 1081-1091.

26 Laux T, Fukami K, Thelen M, Golub T, Frey D, Caroni P. GAP43, MARCKS, and CAP23 modulate $\mathrm{PI}(4,5) \mathrm{P}(2)$ at plasmalemmal rafts, and regulate cell cortex actin dynamics through a common mechanism. J Cell Biol 2000; 149: 1455-1472.

27 Kovalchuk AL, Qi CF, Torrey TA, Taddesse-Heath L, Feigenbaum L, Park SS et al. Burkitt lymphoma in the mouse. J Exp Med 2000; 192: 1183-1190.

28 Zhang JQ, Okumura C, McCarty T, Shin MS, Mukhopadhyay P, Hori M et al. Evidence for selective transformation of autoreactive immature plasma cells in mice deficient in Fasl. J Exp Med 2004; 200: 1467-1478.

29 Qi CF, Zhou JX, Hoon Lee C, Naghashfar Z, Xiang S, Kovalchuk AL et al. Anaplastic, plasmablastic, and plasmacytic plasmacytomas of mice: relationships to human plasma cell neoplasmas and late-stage differentiation of normal B cells. Cancer Res 2007; 67: 2439-2447

30 Kolar GR, Mehta D, Pelayo R, Capra JD. A novel human B cell subpopulation representing the initial germinal center population to express AID. Blood 2007; 109: 2545-2552.

31 Kusam S, Vasanwala FH, Dent AL. Transcriptional repressor BCL-6 immortalizes germinal center-like B cells in the absence of p53 function. Oncogene 2004; 23: 839-844

32 Masuda K, Furuyama T, Takahara M, Fujioka S, Kurinami H, Inagaki S. Sema4D stimulates axonal outgrowth of embryonic DRG sensory neurones. Genes Cells 2004; 9 : 821-829.

33 Kikutani H, Kumanogoh A. Semaphorins in interactions between T cells and antigenpresenting cells. Nat Rev Immunol 2003; 3: 159-167.

34 Hall KT, Boumsell L, Schultze JL, Boussiotis VA, Dorfman DM, Cardoso AA et al. Human CD100, a novel leukocyte semaphorin that promotes B-cell aggregation and differentiation. Proc Natl Acad Sci USA 1996; 93: 11780-11785.

35 Shi W, Kumanogoh A, Watanabe C, Uchida J, Wang X, Yasui T et al. The class IV semaphorin $\mathrm{CD} 100$ plays nonredundant roles in the immune system: defective $\mathrm{B}$ and $\mathrm{T}$ cell activation in CD100-deficient mice. Immunity 2000; 13: 633-642.

36 Watanabe C, Kumanogoh A, Shi W, Suzuki K, Yamada S, Okabe M et al. Enhanced immune responses in transgenic mice expressing a truncated form of the lymphocyte semaphorin CD100. J Immunol 2001; 167: 4321-4328.

37 Kumanogoh A, Watanabe C, Lee I, Wang X, Shi W, Araki H et al. Identification of CD72 as a lymphocyte receptor for the class IV semaphorin CD100: a novel mechanism for regulating B cell signaling. Immunity 2000; 13: 621-631.

38 Pan C, Baumgarth N, Parnes JR. CD72-deficient mice reveal nonredundant roles of CD72 in B cell development and activation. Immunity 1999; 11: 495-506.

39 Trusolino L, Comoglio PM. Scatter-factor and semaphorin receptors: cell signalling for invasive growth. Nat Rev Cancer 2002; 2: 289-300.

40 Conrotto P, Corso S, Gamberini S, Comoglio PM, Giordano S. Interplay between scatter factor receptors and B plexins controls invasive growth. Oncogene 2004; 23: 5131-5137.

41 van der Voort $R$, Taher TE, Keehnen RM, Smit L, Groenink M, Pals ST. Paracrine regulation of germinal center $\mathrm{B}$ cell adhesion through the c-met-hepatocyte growth factor/scatter factor pathway. J Exp Med 1997; 185: 2121-2131.

42 Caroni P. New EMBO members' review: actin cytoskeleton regulation through modulation of $\mathrm{PI}(4,5) \mathrm{P}(2)$ rafts. EMBO J 2001; 20: 4332-4336.

43 Calabrese B, Halpain S. Essential role for the PKC target MARCKS in maintaining dendritic spine morphology. Neuron 2005; 48: 77-90.

44 Stumpo DJ, Bock CB, Tuttle JS, Blackshear PJ. MARCKS deficiency in mice leads to abnormal brain development and perinatal death. Proc Natl Acad Sci USA 1995; 92 : 944-948.

45 Onfelt B, Nedvetzki S, Yanagi K, Davis DM. Cutting edge: Membrane nanotubes connect immune cells. J Immunol 2004; 173: 1511-1513.

46 Rustom A, Saffrich R, Markovic I, Walther P, Gerdes HH. Nanotubular highways for intercellular organelle transport. Science 2004; 303: 1007-1010.

47 Friedel RH, Kerjan G, Rayburn H, Schuller U, Sotelo C, Tessier-Lavigne M et al. Plexin-B2 controls the development of cerebellar granule cells. J Neurosci 2007; 27: 3921-3932.

48 Fleire SJ, Goldman JP, Carrasco YR, Weber M, Bray D, Batista FD. B cell ligand discrimination through a spreading and contraction response. Science 2006; 312 : 738-741

49 Tordjman R, Lepelletier Y, Lemarchandel V, Cambot M, Gaulard P, Hermine 0 et al. A neuronal receptor, neuropilin-1, is essential for the initiation of the primary immune response. Nat Immunol 2002; 3: 477-482.

50 Carmeliet P, Tessier-Lavigne M. Common mechanisms of nerve and blood vessel wiring. Nature 2005; 436: 193-200.

51 Morris JS, Stein T, Pringle MA, Davies CR, Weber-Hall S, Ferrier RK et al. Involvement of axonal guidance proteins and their signaling partners in the developing mouse mammary gland. J Cell Physiol 2006; 206: 16-24.

52 Cascalho M, Wong J, Steinberg C, Wabl M. Mismatch repair co-opted by hypermutation. Science 1998; 279: 1207-1210.

53 Phan TG, Amesbury M, Gardam S, Crosbie J, Hasbold J, Hodgkin PD et al. B cell receptor-independent stimuli trigger immunoglobulin (Ig) class switch recombination 
and production of IgG autoantibodies by anergic self-reactive B cells. J Exp Med 2003; 197: 845-860.

54 Hartley JW, Chattopadhyay SK, Lander MR, Taddesse-Heath L, Naghashfar Z, Morse III HC et al. Accelerated appearance of multiple B cell lymphoma types in NFS/N mice congenic for ecotropic murine leukemia viruses. Lab Invest 2000; 80: 159-169.

55 Morse III HC, Anver MR, Fredrickson TN, Haines DC, Harris AW, Harris NL et al. Bethesda proposals for classification of lymphoid neoplasms in mice. Blood 2002; 100: 246-258.

56 Park SS, Kim JS, Tessarollo L, Owens JD, Peng L, Han SS et al. Insertion of c-Myc into Igh induces B-cell and plasma-cell neoplasms in mice. Cancer Res 2005; 65: 1306-1315.

57 Hartwig C, Veske A, Krejcova S, Rosenberger G, Finckh U. Plexin B3 promotes neurite outgrowth, interacts homophilically, and interacts with Rin. BMC Neurosci 2005; 6: 53.

58 Kramer PR, Wray S. Novel gene expressed in nasal region influences outgrowth of olfactory axons and migration of luteinizing hormone-releasing hormone (LHRH) neurons. Genes Dev 2000; 14: 1824-1834.

59 Kramer PR, Wray S. Nasal embryonic LHRH factor (NELF) expression within the CNS and PNS of the rodent. Brain Res Gene Expr Patterns 2001; 1: 23-26.

60 Balmer CW, LaMantia AS. Loss of Gli3 and Shh function disrupts olfactory axon trajectories. J Comp Neurol 2004; 472: 292-307.

61 Stoeckli ET. Longitudinal axon guidance. Curr Opin Neurobiol 2006; 16: 35-39.

62 Bourke GJ, El Alami W, Wilson SJ, Yuan A, Roobol A, Carden MJ. Slow axonal transport of the cytosolic chaperonin CCT with Hsc73 and actin in motor neurons. J Neurosci Res 2002; 68: 29-35.
63 Roobol A, Holmes FE, Hayes NV, Baines AJ, Carden MJ. Cytoplasmic chaperonin complexes enter neurites developing in vitro and differ in subunit composition within single cells. J Cell Sci 1995; 108 (Part 4): 1477-1488.

64 Sternlicht H, Farr GW, Sternlicht ML, Driscoll JK, Willison K, Yaffe MB. The t-complex polypeptide 1 complex is a chaperonin for tubulin and actin in vivo. Proc Natl Acad Sci USA 1993; 90: 9422-9426.

65 Uwabe K, Gahara Y, Yamada H, Miyake T, Kitamura T. Identification and characterization of a novel gene (neurorep 1) expressed in nerve cells and up-regulated after axotomy. Neuroscience 1997; 80: 501-509.

66 Brennan MD, Condra J. Transmission disequilibrium suggests a role for the sulfotransferase-4A1 gene in schizophrenia. Am J Med Genet B Neuropsychiatr Genet 2005; 139: 69-72.

67 Falany CN, Xie X, Wang J, Ferrer J, Falany JL. Molecular cloning and expression of novel sulphotransferase-like cDNAs from human and rat brain. Biochem J 2000; 346 (Part 3): 857-864.

68 Liyou NE, Buller KM, Tresillian MJ, Elvin CM, Scott HL, Dodd PR et al. Localization of a brain sulfotransferase, SULT4A1, in the human and rat brain: an immunohistochemical study. J Histochem Cytochem 2003; 51: 1655-1664.

69 Severt WL, Biber TU, Wu X, Hecht NB, DeLorenzo RJ, Jakoi ER. The suppression of testis-brain RNA binding protein and kinesin heavy chain disrupts mRNA sorting in dendrites. J Cell Sci 1999; 112 (Part 21): 3691-3702.

70 Chiu CS, Brickley S, Jensen K, Southwell A, McKinney S, Cull-Candy S et al. GABA transporter deficiency causes tremor, ataxia, nervousness, and increased GABA-induced tonic conductance in cerebellum. J Neurosci 2005; 25: 3234-3245.

Supplementary Information accompanies the paper on Immunology and Cell Biology website (http://www.nature.com/icb). 